\title{
PERILAKU WANITA USIA SUBUR (WUS) DALAM PARTISIPASI PROGRAM DETEKSI DINI KANKER PAYUDARA DENGAN PEMERIKSAAN PAYUDARA KLINIS (SADANIS) DI WILAYAH KERJA PUSKESMAS JATINOM : STUDI FENOMENOLOGI
}

\author{
Istianna Nurhidayati ${ }^{1}$ Chori Elsera ${ }^{2}$ Dewi Widayanti ${ }^{3}$ \\ Prodi S1 Keperawatan Stikes Muhammadiyah Klaten \\ e-mail : istiannanurhidayati@gmail.com
}

\begin{abstract}
Breast cancer is a cancer with prevalence ranked second in Indonesia. Regular checkups are regularly performed as an effort to prevent and detect early cancer. The study aims to explore the meaning and meaning in depth of Women's Age Fertile experience (WAF) in participating in early detection of breast cancer. This research uses qualitative design with phenomenological approach. The number of research samples were 6 participants. The results obtained knowledge of malignant cancer of malignant cancer. The conclusion of this study is the experience of women of childbearing age in the participation of early breast cancer detection programs with different SADANIS - there are some who have a good health awareness and there are feel shy and scared when examined.
\end{abstract}

Keyword : women's age fertile (WAF) behavior, Participation detection program breast cancer, Clinical breast examination $(C B E)$.

Abstrak

Penyakit kanker payudara merupakan penyakit kanker dengan prevalensi menduduki peringkat ke dua di Indonesia. Tingginya prevalensi kanker di Indonesia perlu dicermati dengan tindakan pencegahan dan deteksi dini yang telah dilakukan oleh penyedia layanan kesehatan. Kasus kanker yang ditemukan pada stadium dini serta mendapat pengobatan yang cepat dan tepat akan memberikan kesembuhan dan harapan hidup lebih lama. Pemeriksaan rutin secara berkala dilakukan sebagai upaya pencegahan dan deteksi dini kanker. Penelitian bertujuan menggali arti dan makna secara mendalam pengalaman Wanita Usia Subur (WUS) dalam berpartisipasi melakukan deteksi dini kanker payudara. Penelitian ini menggunakan desain kualitatif dengan pendekatan fenomenologis. Jumlah sampel penelitian sebanyak 6 partisipan. Hasil penelitian diperoleh pengetahuan mengenai kanker payudara kanker ganas yang berbahaya. Sumber informasi kanker payudara. Persepsi kerentanan, tingkat keparahan, manfaat, hambatan, isyarat untuk bertindak, kepercayaan diri Wanita Usia Subur tentang deteksi dini kanker payudara dengan menggunakan SADANIS mengenai pemahaman partisipan terhadap faktor resiko kanker payudara, keparahan kanker payudara, kendala sebelum melakukan SADANIS, manfaat setelah mengetahui kanker payudara dan sadanis, kondisi emosial wus saat berpartisipasi melakukan sadanis, persiapan untuk melakukan sadanis, tindakan setelah mengetahui kanker payudara. Harapan wanita Usia Subur kepada pelayanan kesehatan dalam kesehatan reproduksi dengan meningkatkan kualitas pelayanan kesehatan reproduksi di Puskemas Jatinom. Kesimpulan penelitian ini adalah pengalaman wanita usia subur dalam partisipasi program deteksi dini kanker payudara dengan SADANIS berbeda - beda ada yang memiliki kesadaran kesehatan yang baik dan ada yang merasa sungkan dan takut saat diperiksa. Hal ini terjadi karena masing - masing partisipan memiliki kepercayaan kesehatan dan faktor pendukung melakukan pemeriksaan yang berbedabeda.

Kata kunci : Perilaku wanita usia subur, Program deteksi kanker payudara, SADANIS)

\section{PENDAHULUAN}

Kanker payudara merupakan keganasan pada jaringan payudara yang dapat berasal dari epitel duktus maupun lobulusnya. Kanker bisa mulai tumbuh di dalam kelenjar susu, saluran susu, jaringan lemak 
maupun jaringan ikat pada payudara yang merupakan kanker nomor dua yang terjadi pada perempuan. Survey WHO (2015) memaparkan 8-9 persen perempuan mengalami kanker payudara.

Kanker payudara merupakan juga merupakan jenis kanker terbanyak di Indonesia, angka insidensi kanker payudara adalah 12/100.000 wanita (Komite Penanggulangan Kanker Nasional, 2015, h1). Pusat Data dan Informasi Kementrian Kesehatan RI (2015), kanker payudara mempunyai presentase kasus baru sebesar 43,3\% dan presentase kematian sebesar 12,9 $\%$. Kanker payudara merupakan penyakit kanker tertinggi kedua di Indonesia dengan jumlah penderita sebanyak 61.682.

Peningkatan penderita kanker payudara pada perempuan dipengaruhi oleh beberapa faktor. Sunarti, Yusran, Pratiwi (2017) dan Yulianti, Setyawan, sutiningsih (2016) menyimpulkan faktor yang mempengaruhi kanker payudara pada perempuan adalah riwayat kanker payudara pada keluarga, aktivitas fisik/ olah raga, penggunaan kontrasepsi hormonal.

Angka prevalensi yang meningkat memberikan dampak pada penderita kanker payudara. Dampak yang ditimbulkan kanker payudara sangat kompleks yaitu mulai dari psikologis, fisik, sosial dan peningkatan pembiayaan kesehatan Liu et al, (2014). Pengendalian dan dampak kanker payudara dapat dikurangi dengan meningkatkan kesadaran deteksi dini kanker payudara. Ketika kanker payudara terdeteksi dini dan diagnosis serta pengobatan yang mamadai tersedia, maka ada kesempatan kanker payudara dapat disembuhkan (InfoDatin, 2013, h1).

Wijaya, Laga (2016) menggambarkan skrining dini kanker payudara pada wanita usia dewasa di wilayah kerja Puskesmas Pandak I Bantul Yogyakarta, penilaian diberikan sesuai dengan data yang didapat terkait skrining kanker payudara di Wilayah Kerja Puskesmas Pandak I Bantul adalah kurang (76,7\%). Skrining ditujukan untuk mendapatkan kanker payudara dini sehingga hasil pengobatan menjadi efektif dengan demikian akan menurunkan kemungkinan kekambuhan, menurunkan mortalitas dan memperbaiki kualitas hidup. Beberapa tindakan untuk skrining adalah : 1. Periksa Payudara Sendiri
(SADARI), 2. Periksa Payudara Klinis (SADANIS), 3. Mammografi skrining.

Program pencegahan kanker payudara

Pemerintah mengatur pelayanan kesehatan masyarakat dalam Permenkes Indonesia Nomor 43 tahun 2016 tentang standar pelayanan minimum bidang kesehatan. Jumlah WUS yang dilakukan deteksi dini kanker payudara di Jawa Tengah tahun 2016 dilaporkan sebanyak 56,337 WUS atau $1.27 \%$ dari perempuan usia 30-50 tahun.

Jumlah WUS yang melakukan SADANIS pada tahun 2015 sebanyak 3.560 WUS atau 1,22 \%, tahun 2016 sebanyak 2.409 atau $0,82 \%$ mengalami penurunan disebabkan adanya hambatan dalam pelaksanaan SADANIS kurangnya kesadaran dan WUS dalam melakukan deteksi dini. Puskesmas Jatinom mempunyai program untuk mencapai SPM enam tentang pelayanan kesehatan pada usia produktif yaitu pelayanan skrining kesehatan usia 15-59 tahun. Program ini bertujuan meningkatkan taraf kesehatan pada kelompok usia produktif dan melakukan deteksi dini kanker payudara, sehingga dapat menurunkan angka mortalitas dan morbiditas karena penyakit tersebut.

Tujuan khusus pelayanan kesehatan pada WUS, puskesmas Jatinom sebagai salah satu puskesmas yang mendapatkan pelatihan dalam pemeriksaan kanker payudara dengan SADANIS yang dilakukan oleh dokter dan bidan, membuka pelayanan SADANIS secara rutin setiap minggunya pada hari rabu.Penelitian yang dilakukan Hanifah (2015,h11) menyatakan, partisipasi pemeriksaan dini kanker payudara dipengaruhi oleh faktor sikap, dukungan keluarga dan keterpaparan informasi.

Berdasarkan latarbelakang diatas maka peneliti tertarik melakukan penelitian "Bagaimana perilaku Wanita Usia Subur (WUS) dalam partisipasi program deteksi dini kanker payudara dengan Pemeriksaan Payudara Klinis (SADANIS) di wilayah kerja Puskesmas Jatinom?".

\section{METODE}

Metode penelitian yang digunakan kualitatif untuk dapat mengeksplorasi secara detail dan mendalam pada Wanita Usia Subur (WUS) dalam pengalaman perilaku WUS untuk melakukan deteksi dini SADANIS. 
Partisipan yang dipilih untuk penelitian ini adalah Wanita Usia Subur (WUS) berusia 3040 tahun yang telah mendapatkan penyuluhan mengenai kanker payudaradan melakukan SADANIS di Puskesmas Jatinom. Populasi dalam penelitian ini sebanyak 57 WUS di wilayah kerja Puskesmas Jatinom pada tahun 2017. Teknik sampling dalam penelitian ini adalah purposful/purposive sampling. Penelitian ini tersaturasi pada partisipan ke 6.

\section{HASIL DAN PEMBAHASAN}

Penelitian ini didapatkan hasil 10 tema: Tema 1 : kanker payudara kanker ganas berbahaya

Persepsi yang teridentifikasi dari WUS tentang kanker payudara adalah kanker payudara itu kanker yang ada di payudara yang sifatnya ganas berbahaya dan bisa mematikan. Ungkapan partisipan :

"Soalnya kanker itu kan ganas bisa mematikan..." (P2)

"Kanker payudara itu penyakit yang berbahaya mungkin, mematikan..." (P6)

Kanker merupakan pertumbuhan abnormal sel secara terus menurus yang tidak terkoordinasi dengan jaringan lain sehingga berbahaya bagi tubuh. Kanker payudara merupakan ancaman serium atau jenis penyakit ganas yang sangat ditakuti oleh kaum wanita karena kanker payudara menempati urutan kedua setelah kanker leher rahim.

Kanker payudara merupakan kanker dengan presentase kasus baru tertinggi yaitu sebesar 43,3\% dan presentase kematian akibat kanker payudara 12,9 \% (Kemenkes RI, 2015, h12).

\section{Tema 2 : Sumber Informasi Kanker Payudara}

Sumber informasi yang didapatkan oleh WUS dalam mendapatkan pengetahuan mengenai kanker payudara. Sumber informasi didapatkan dari petugas kesehatan, media elektronik, dan lingkungan.

"Dari pertemuan posyandu, pertemuan ibuibu PKK, dari yayasan peduli kanker juga memberikan penyuluhan..."(P4)

"Terus lihat di tv sama di internet.."(P6)

Biasanya curhat mbak sama temen - temen sesame ibu - ibu waktu dirumah sakit...."(P3)

Sumber informasi yang diterima berpengaruh terhadap peningkatan pengetahuan partisipan sehingga partisipan memiliki rasa tau dan akan memiliki sikap bertindak setelah mendapat pengetahuan. Sumber informasi adalah asal dari suatu informasi atau data yang diperoleh (Notoatmodjo, 2003,h76)

Hasil penelitian yang dilakukan oleh Novasari, Dinnia Hanivah (2016,h45), menyatakan presentase terbesar paparan media informasi pada kelompok tidak terpaapar terdapat pada pengetahuan mengenai kanker payudara dan praktek pemeriksaan payudara kurang $(90,5 \%)$, presentase terbesar paparan media informasi pada kelompok cukup terpapar terdapat pada pengetahuan mengenai kanker payudara dan praktek pemeriksaan payudara cukup $(66,7 \%)$ dan presentase terbesar paparan media informasi pada kelompok tidak terpapar terdapat pada pengetahuan mengenai kanker payudara dan praktek pemeriksaan payudara baik $(33,3 \%)$.

\section{Tema 3: Faktor resiko kanker payudara}

Hasil penelitian ini juga mengidentifikasi tema tentang faktor resiko kanker payudara yang kemungkinan terjadinya kanker paydura. Partisipan menyebutkan faktor resiko kanker payudara meliputi usia, menarche dini, pola makan, pemakaian $\mathrm{BH}$, genetik, ibu yang tidak menyusui dan KB. Ungkapan partisipan :

"Yaa usia itu diatas 50 tahun..." (P1)

"Dulu waktu pertama kali mens umurnya kurang dari 12 tahun..." (P2)

"Pola makan yang tidak baik kayak tadi mie instant,makanan cepat saji..." (P2)

"Pakai BH itu harusnya dilepas kalau tidur, tidak boleh memakai kawat juga... "(P1)

"Faktor genetik mempengaruhi...." (P3)

"Pakai KB itu mbak kalau lama makainya..." (P2)

Penyebab pasti kanker payudra belum diketahui, diperikirakan multifaktorial proses timbulnya kanker payudra merupakan kejadian kompleks yang melibatkan berbagai faktor. Selain adanya defek pada gen BRCA 1 dan BRCA 2, masih banyak kelainan yang pada prinsipnya meningkatkan aktivitas proliferasi sel serta kelainan yang menurunkan atau menghilangkan regulasi kematian sel (Indrati, 2018,h31).

Hasil penelitian yang dilakukan Priyatin (2013,h42), Semakin kuat dugaan usia menarche berisiko merupakan faktor resiko terjadinya kanker payudara memiliki resiko 
2,638 kali lebih tinggi untuk mengalami kanker payudara. Beberapa penelitian menunjukkan pola makanan yang berlemak dan makanan yang tidak sehat yang dikonsumsi dengan frekuensi tinggi akan dapat meningkatkan resiko terkena kanker payudara. Pada diet lemak yangtinggi akan meningkatkan produksi estrogen karena meningkatnya pembentukan jaringan adepose. Peningkatan konsentrasi estrogen dalam darah akan meningkatkan risiko terkena kanker payudara karena efek proliferasi dari estrogen pada duktus ephitelium payudara (Indrati, 2018, h37). kandungan esterogen dan progesteron pada kandungan kontrasepsi oral akan memberikan efek proliferasi berlebih pada duktus ephitelium payudara. Berlebihnya proliferasi sel dengandiikuti hilangnya kontrol atas proliferasi sel dan pengaturan kematian sel yang sudah terprogram akan mengakibatkansel payudara berproliferasi secara terus menerus tanpa adanya batas kematian.

Hasil penelitian yang dilakukan Priyatin (2013,h46), menunjukkan hubungan yang signikan lama penggunaan kontrasepsi hormonal berisiko mengurangi risiko kejadian kanker payudara. Semakin kuat dugaan penggunaan kontrasepsi hormona merupakan faktor resiko terjadinya kanker payudara memiliki resiko 0,513 kali lebih rendah untuk mengalami kanker payudara.

Hasil penelitian yang dilakukan Priyatin (2013,h46), menunjukkan hubungan yang signikan riwayat keluarga berisiko mempertinggi kejadian kanker payudra. Semakin kuat riwayat keluarga berisiko merupakan faktor resiko terjadinya kanker payudara memiliki resiko 6,938 kali lebih tinggi untuk mengalami kanker payudara.

Indrati (2018,h38), mengatakan kebiasaan menyusui berhubungan dengan siklus hormonal. Proses setelah melahirkan kadar hormon estrogen dan hormon progesteron yang tinggi selama masa kehamilan akan menurun dengan tajam. Kadar hormon estrogen dan hormon progesteron akan tetap rendah selama masa menyusui. Menurunnya kadar hormon estrogen dan hormon progesteron dalam darah selama menyusui akan mengurangi pengaruh hormon tersebut terhadap proses proliferasi jaringan termasuk jaringan payudara.

Hasil penelitian menunjukkan bahwa riwayat tidak menyusui meningkatkan risiko kanker payudara. Wanita yang tidak pernah menyusui akan memiliki risiko 2,118 kali lebih tinggi untuk mengalami kanker payudara dibandingkan wanitayang pernah menyusui (Priyantin, 2013,h41).

\section{Tema 4 : Keparahan kanker payudara}

Keparahan kanker payudara dapat menyebabkan keparahan fisik, kematian, payudara membusuk, mastektomi, tidak bisa menyusui terjadi metastasis dan terjadinya gangguan emosional.

"Parah mbak dari fisik pasti sakit..."(P1)

"Paling parah itu bisa menyebabkan kematian..."(P3)

"Benjolannya yang makin membesar bisa membusuk..." (P6)

Kalau parah terus dioperasi kan nggak punya payudara..." (PI)

"Payudaranya sampai diangkat, kehilangan payudara..."(P2)

Tidak bisa menyusui

"Terus nggak bisa menyusui... "(P6)

"Kalau dioperasi sekali terus tumbuh lagi menjalar ke organ tubuh lain..." (P4)

"Bisa menyebar ke tubuh yang lain..." (P5)

Gangguan emosional

Semangat hidupnya hilang.." (P6)

Kanker payudara dapat memberikan komplikasi metastase jaringan sekitarnya dan juga melalui saluran limfe dan pembuluh darah ke organ-organ lain. (Rasjidi, 2010,h40). Kanker payudara dapat memberikan dampak secara fisik maupun psikologis. Gangguan secara fisik biasanya berasal dari rasa sakit dan ketidaknyamanan. Dampak psikologis yang muncul akibat kanker payudara adalah kehilangan semangat kecemasan, depresi, dan stres (Winda, 2013. 44). Dampak kanker payudara pada stadium II dan III yang harus dilakukan mastektomi dapat menghambat proses perkembangan sel kanker dan umumnya penderita akan kehilangan sebagian atau seluruh payudara, mati rasa pada kulit serta kelumpuhan apabila tidak mendapatkan penanganan secara seksama (Dewy, 2004,h43).

\section{Tema 5 : Kendala Sebelum Melakukan} SADANIS

Hasil penelitian mengidentifikasi kendala sebelum melakukan SADANIS yang dirasakan partisipan meliputi kendala perasaan 
takut, waktu, dan tidak ada kendala yang dirasakan oleh partisipan.

"takut diperiksa kayak apa gitu.." (P5)

"kendalane masalah waktu soale kan ngantri suwe.." (P3) Kendalanya masalah waktu soalnya kan antrinya lama

"Prinsip saya ya harus ikut mbak kalau ada tes seperti itu ....."(P4)

Hambatan dalam melakukan pemeriksaan payudara, seperti sulit dalam mengingat kapan harus melakukan pemeriksaan ulang, takut jika menemukan benjolan, serta rasa malu. Motivasi manusia akan lebih cepat dan bersungguh-sungguh dalam melakukan tindakan serta menyadari akan pentingnya suatu perilaku dan dirasakan sebagai suatu kebutuhan (Hanifah,2015,h42).

\section{Tema 6 : Manfaat Setelah} Mengetahui Kanker Payudara Dan Sadanis

Setelah mengetahui informasi yang diberikan oleh petugas kesehatan dan sumber informasi lainnya partisipan memiliki peningkatan kewaspadaan mengenai kanker payudara untuk berhati - hati agar tidak terkena kanker payudara dengan menjauhi segala faktor penyebab yang dapat menyebabkan kanker payudara.

"Kalau dirumah ngraba ngraba cuman sebisanya mbak,kalau di puskesmas jadi tau yang bener...." (P2)

"Manfaatnya baik mbak, bisa lebih waspada.." (P5)

Manfaat yang dirasakan adalah salah satu kepercayaan pada kemanjuran dan tindakan yang disarankan untuk mengurangi risiko kesehatan. Manfaat yang dirasakan mengambil tindakan kesehatan, sikap perubahan perilaku kesehatan bergantung pada pandangan seseorang tentang manfaat kesehatan untuk melakukan tindakan kesehatan Skinner (1998) dalam Glanz, Rimer dan Viswanath, 2008,h59).

Penelitian yang dilakukan oleh Suroyo (2015,h43), menyatakan rendahnya pengetahuan atau informasi tentang penyakit kanker serta usaha pencegahan deteksi dini menyebabkan banyak wanita yang belum tertarik atau kurang berminat untuk melakukan usaha deteksi ini.

Tema 7 :Kondisi emosional WUS saat berpartisipasi melakukan SADANIS
Hasil penelitian mengidentifikasi kondisi emosional wus saat berpartisipasi melakukan sadanis yaitu perasaaan sungkan, biasa - biasa saja saat melakukan, setelah mendapatkan hasil pemeriksaan partisipan menyatakan merasakan senang, lega dan puas karena tidak terdapat benjolan saat dilakukan pemeriksaan

"Perasaanya seneng banget plong..." (P5)

Legaa nggak terkena baik semua..” (P2)

"Yaa puas tidak ada gejala gitu.." (P4)

"Disuruh buka baju diperiksa ya ngikut aja agak malu juga...” (Pl)

"Disana diperiksa yaa dicek diraba gitu biasa sama ibu bidannya sama - sama perempuan..." (P2)

Pemeriksaan payudara yang dilakukan menyebabkan seseorang merasakan takut jika menemukan benjolan dan rasa malu (Hanifah,2015,h42).Motivasi intrinsik yang rendah ini disebabkan oleh rendahnya kekuatan yang muncul dari dalam diri partisipan yang menjadi pendorong dalam melakukan pemeriksaan payudara. Motivasi intrinsik yang rendah ini dipengaruhi oleh kebutuhan serta tanggung jawab dalam pelaksanaan pemeriksaan payudara, keinginan untuk melaksanakan pemeriksaa payudara.

\section{Tema 8 : Persiapan Untuk Melakukan SADANIS}

SADANIS dilakukan dengan berbagai persiapan sebelum melakukannya, perlu dilakukan persiapan mental untuk memantapkan diri untuk melakukan pemeriksaan, perlu dilakukan kelengkapan administrasi yang dibutuhkan seperti kartu identitas diri, KK, KIS dan surat lain yang dibutuhkan. Kebersihan diri dilakukan sebelum melakukan pemeriksaan, dan persiapan dukungan dari keluarga juga diperlukan agar partispan mau melakukan pemeriksaan.

"Mau periksa ya mandi haahaa.." (P2)

"Persiapan mental ya harus siap apapun yang terjadi yaa wis pokoke..." (P2)

"Kalau saya sudah biasa periksa jadi yaa biasa aja..."(P3)

Terus bawa surat- surat yang dibutuhkan.." (P6) 
"Dukungan dari suami minta ijin sama suami.." (P2)

Dalam pelaksanaan pemeriksaan payudara, diperlukan suatu kemampuan dan motivasi yang kuat untuk melaksanakannya. Tidak hanya mengetahui segala sesuatu yang berkaitan dengan pemeriksaan payudara, namun juga diperlukan motivasi untuk melaksanakannya sebagai upaya deteksi dini kanker payudara. Sehingga apabila ditemukan adanya suatu kelainan, dapat ditanggulangi lebih dini dan mengurangi risiko berkembangnya penyakit menuju tahap selanjutnya (Hanifah,2015,h43). Persiapan untuk melakukan sadanis dijelaskan dengan penelitian dilakukan oleh Mayulu, Nelly (2013, h39), menyatakan persiapan untuk melakukan sadanis perlu dukungan keluarga, keluarga merupakan orang terdekat dengan responden dalam berinteraksi dan dalam mengambil keputusan terutama dalam menentukan kemana akan mencari pertolongan atau pengobatan.

\section{Tema 9 :Tindakan Setelah Mengetahui Kanker Payudara}

Hasil penelitian teridentifikasi tindakan yang dilakukan WUS setelah mengetahui informasi mengenai kanker payudara. Setelah mengikuti penyuluhan dan pemeriksaan di Puskesmas Jatinom WUS melanjutkan tindakan sadari dirumah secara rutin dan melakukan sadanis di puskesmas disetiap tahunnya.

"Dilakukan dirumah sendiri kan biasanya pas mandi to mbak apa pastidur.." (P5)

"rutin kalau habis mandi beberapa hari setiap hari.." (P4)

Sebelum melakukan sadanis dipengaruhi perilaku seseorang atau masyarakat tentang kesehatan ditentukan oleh pengetahuan, sikap, kepercayaan, dan tradisi dari orang atau masyarakat yang berangkutan (Notoatmodjo,2007,h64) menyatakan bahwa Pengetahuan yang memadai akan membantu dalam pembentukan perilaku individu terhadap suatu hal.

Penelitian yang dilakukan oleh Sondakh, Joyce $(2017, \mathrm{~h} 41)$ menunjukkan bahwa sebagian besar responden, menjawab baik sebanyak 31 responden $(57,4 \%)$, sedangkan yang menjawab kurang baik sebanyak 23 responden $(42,6 \%)$. Sikap baik terhadap deteksi dini kanker payudara metode SADARI memiliki arti bahwa responden cenderung akan melakukan deteksi dini untuk mengetahui secara awal jika ada kelainan pada payudara.

\section{Tema 10 : Kualitas Pelayanan Kesehatan Reproduksi Di Puskesmas Jatinom}

Hasil penelitian teridentifikasi kualitas pelayanan kesehatan reproduksi di Puskesmas Jatinom, petugas kesehatan sudah memilikisikap yang ramah, dari segi prosedural sudah melakukan pelayanan yang baik dan memuaskan

"Pelayanannya bagus baik, sudah memuaskan..."(P4)

"Kalau bisa ya loket pendaftarannya ditambah biar nggak ngantri lama.." (P4)

Pelayanan yang dimaksud adalah pelayanan yang cepat, tepat, murah, dan ramah, selain dapat meningkatkan taraf kesehatan masyarakat pelayanan yang maksimal juga menunjang kepuasan masyarakat (Priyono, 2014, h244). Kepuasan merupakan suatu evaluasi perasaan dari suatu kinerja atau pelayanan sejauh mana suatu kinerja, produk ataupun pelayanan dapat memenuhi harapan (Kotler \& Amstrong, 2001, h9; Priyono, 2014, h249).Pelayanan dapat memenuhi harapan alur pelayanan yang tidak berbelit, jelas, dan dengan proses yang cepat. Akses pelayanan yang efektif dan efisien akan memudahkan pemanfaatan pelayanan kesehatan oleh individu atau keluarga sehingga dapat tercapai peningkatan status kesehatan dan pemanfaatan pelayanan kesehatan (Priyono, 2014, h256).

Hasil penelitian ini sesuai dengan penelitian Anjaryani (2009, h66) yang mengidentifikasi faktor-faktor yang mempengaruhi kepuasan pasien terhadap pelayanan perawatan di Rumah sakit dengan hasil kepuasan pasien ditinjau dari aspek kemampuan pelayanan yang akurat, daya tanggap dan kecepatan pelayanan, serta rasa empati dan komunikasi yang baik oleh petugas kesehatan.

\section{KESIMPULAN}

Pengetahuan WUS tentang kanker payudara WUS memaknai penyakit kanker payudara adalah kanker payudara kanker ganas yang berbahaya. Sumber informasi 
WUS dalam pengetahuannya tentang kanker payudara. Sumber informasi Wanita Usia Subur dalam pengetahuannya tentang kanker payudara ,mendapatkan informasi dari sumber berupa media elektronik,lingkungan dan petugas kesehatan.

Kerentanan, tingkat keparahan, manfaat, hambatan, isyarat untuk bertindak, kepercayaan diri WUS tentang deteksi dini kanker payudara dengan SADANIS Teridentifikasinya pemahaman partisipan menge fnaiaktor resiko kanker payudara, keparahan kanker payudara dapat menyebabkan kematian, membusuk, dilakukannya mastektomi,ibu tidak bisa menyusui,metastasis, dan adanya gangguan emosional, kendala yang mereka alami sebelum melakukan SADANIS berupa adanya rasa takut, masalah waktu, dan tidak ada kendala yang dirasakan.

Manfaat setelah mengetahui kanker payudara dan SADANIS dapat meningkatkan pengetahuan dan kewaspadaan., Kondisi emosional WUS saat berpartisipasi melakukan SADANIS merasakan senang, lega, puas, sungkan dan percaya diri. Partisipan menjelaskan persiapan yang dilakukan sebelum SADANIS dengan melakukan kebersihan diri, persiapan mental, kelengkapan administrasi dan dukungan keluarga. tindakan yang dilakukan setelah mengetahui kanker payudara dengan melakukan pemeriksaan secara rutin.

Harapan WUS kepada pelayanan kesehatan dalam kesehatan reproduksi

Harapan WUS kepada pelayanan kesehatan teridentifikasinya kualitas pelayanan kesehatan reproduksi di Puskesmas Jatinom dari segi sikap dan prosedural. Partisipan menyatakan harapan dari kualitas pelayanan kesehtan reproduksi di Puskesmas Jatinom agar lebih responsif, kompeten dan meningkatkan komunikasi.

\section{DAFTAR PUSTAKA}

Allender, AJ 2014.Community \& Public Health Nursing Promoting the Public's Health. China : Wolters Kluwer Health.Halaman 769.
Denzin, N.K \& Lincoln. 2009.Handbook of qualitative research. Jakarta : Pustaka Pelajar. Halaman 3.

Dewy, Indryani (2012). Gambaran Motivasi dan Tingkat Pengetahuan Mengenai Kanker Payudara Pada Perempuan Yang Melakukan Mamografi. Skripsi Keperawatan UI. Halaman 19. Tersedia dalam https://scholar.google.co.id/scholar?hl $=\mathrm{id} \&$ as_sdt $=0 \% 2 \mathrm{C} 5 \& \mathrm{q}=$ gambaran $+\mathrm{m}$ otivasi+dan+tingka+pengetahuan+men genai+kanker+payudara\&btnG [Diakses 1 Februari 2018]

Dinkes. 2016. Buku Saku Kesehatan. Dinas Kesehatan Provinsi Jawa Tengah.

Direktorat Pengendalian Penyakit Tidak Menular Direktorat Jenderal PP dan PL Departemen Kesehatan RI. Buku Saku Pencegahan kanker leher Rahim \& kanker payudara. 2009.

Kemenkes RI. 2016. Profil Kesehatan Indonesia.Kementerian Kesehatan RI : Jakarta

Kementerian Kesehatan RI Direktorat Jenderal Pengendalian Penyakit dan Penyehatan Lingkungan Direktorat Pengendalian Penyakit Tidak Menular. Panduan Program Nasional Gerakan Pencegahan dan Deteksi Dini Kanker Leher Rahim dan Kanker Payudara. 2015.

Komite Penanggulangan Kanker Nasional. Panduan Penatalaksanaan Kanker Payudara. 2015.

Kusuma, Prima Daniyati. Susilawati, Dwi (2013). Persepsi Mahasiswa Program Studi Ilmu Keperawatan Universitas Diponegoro Angkatan 2006 Jalur Reguler yang Berisiko Terkena Kanker Payudara Terhadap Perilaku SADARI. Skripsi Universitas Diponegoro. Tersedia dalam http://jurnal.unimus.ac.id/index.php/J KMat/article/view/994. [Diakses 5 Februari 2018]

Polit,FD \& Back,CT. 2014. Essential of Nursing Research Apprraising 
Evidence for Nursing Practice. China: Wolters Kluwer Healt. Halaman 293.

Pusat Data dan Informasi Kementrian Kesehatan (INFODATIN). 2013. Situasi penyakit kanker. Halaman 3. Tersedia dalam http://www.depkes.go.id/resources/ download/pusdatin/infodatin/infoda tin-kanker.pdf. Diakses 22 Februari 2018.

Pusat Data dan Informasi Kementrian Kesehatan (INFODATIN). 2016. Kanker Payudara. Halaman 8.

Putri, Intan Mutiara (2017). Hubungan Self Efficacy Dengan Perilaku Periksa Payudara Sendiri (SADARI) Pada Wanita Di Kecamatan Tegalrejo Kota Yogyakarta. Skripsi Universitas Aisyiyah Yogyakarta. Tersedia dalam http://digilib.unisayogya.ac.id/2405/

[Diakses 12 Februari 2018]

Rasjidi, I. 2010. Epidemiologi Kanker Pada Wanita. Jakarta : Sagung Seto.

Sari, Tutyan Mia (2013). Faktor-Faktor yang Berhubungan dengan Perilaku Deteksi Dini Kanker Payudara pada Wanita Usia Subur Di Desa Dawung Kebakkramat Karanganyar.Skripsi Universitas Muhammadiyah Surakarta. Tersedia dalam http://eprints.ums.ac.id/27262/

[Diakses 26 Januari 2018]

Sofi. 2015. Stop Kanker. Yogyakarta : Istana Media.
Sudarmi (2017). Implementasi Deteksi Dini Kanker Payudara dan Kanker Leher Rahim dengan Menggunakan Metode CBE dan IVA di Kabupaten Lampung Selatan. Jurnal Kesehatan Politeknik Kesehatan TanjungKarang. Tersedia dalam https://www.poltekkestjk.ac.id/ejurnal/index.php/JK/article/v iew/483 [Diakses 6 Februari 2018]

Susilowati (2013). Tingkat Pengetahuan Wanita Usia Subur (WUS) Tentang Deteksi Dini Kanker Payudara Di Dusun Macanmati Kecamatan Gesi Kabupaten Sragen Tahun 2013. Skripsi STIKES Kusuma Husada Surakarta. Tersedia dalam https://scholar.google.co.id/scholar?hl $=\mathrm{id} \&$ as_sdt $=0 \% 2 \mathrm{C} 5 \& \mathrm{q}=$ tingkat+peng etahuan+tentang+deteksi+kanker+pay udara+sragen \&btnG $=[$ Diakses 14 Februari 2018]

Wahyudin, Rajab. 2009. Buku Ajar Epidemiologi untuk Mahasiswa Kebidanan. Jakarta : EGC.

Wijaya, Intan Laga (2016). Gambaran skrining dini kanker payudara pada wanita usia dewasa di Wilayah kerja puskesmas pandak I bantul Yogyakarta. Skripsi STIKES Jendral Achmad Yani Yogyakarta. Tersedia dalam https://scholar.google.co.id/scholar?hl $=\mathrm{id} \&$ as_sdt $=0 \% 2 \mathrm{C} 5 \& \mathrm{q}=\mathrm{ntan}+$ laga + wi jaya\&btnG $=$ [ Diakses 21 Februari 2018] 